[19] Pednekar, M. S., Hakama, M., Hebert, J. R., Gupta, P. C. (2008). Association of body mass index with all-cause and cause-specific mortality: findings from a prospective cohort study in Mumbai (Bombay), India. International Journal of Epidemiology, 37 (3), 524-535. doi: 10.1093/ije/dyn001

[20] Di Cesare, M., Bennett, J. E., Best, N., Stevens, G. A., Danaei, G., Ezzati, M. (2013). The contributions of risk factor trends to cardiometabolic mortality decline in 26 industrialized countries. International Journal of Epidemiology, 42 (3), 838-848. doi: 10.1093/ije/dyt063

[21] Ezzati, M., Riboli, E. (2012). Can Noncommunicable Diseases Be Prevented? Lessons from Studies of Populations and Individuals. Science, 337 (6101), 1482-1487. doi: 10.1126/science.1227001

\title{
RESECTION OPERATIONS IN SURGICAL TREATMENT OF PATIENTS WITH CHRONIC PANCREATITIS COMPLICATED BY BILIARY HYPERTENSION
}

\author{
Volodymyr Pylypchuk \\ Department of surgery of the Institute of Postgraduate \\ Education of the Ivano-Frankivsk National Medical University \\ 91 Fedkovycha str., Ivano-Frankivsk, Ukraine, 76000 \\ vipdoz@ukr.net \\ Andriy Yavorskyy \\ Ivano-Frankivsk Regional Clinical Hospital \\ Ivano-Frankivsk National Medical University \\ 91 Fedkovycha str., Ivano-Frankivsk, Ukraine, 76000 \\ burg555@mail.ru \\ Galyna Shabat \\ National Cancer Institute of Ukraine \\ 33/43 Lomonosova str., Kyiv, Ukraine, 03022 \\ galyna.shabat@gmail.com \\ Marino Marco Vito \\ Department of Surgery \\ Europen Institute of Oncology, Milan, Italy \\ 435 Giuseppe Ripamonti str., Milan, Italy, 20141 \\ marco.vito.marino@gmail.com
}

\begin{abstract}
Surgical treatment was applied in 145 patients with complicated forms of chronic pancreatitis (CP) at the department of surgery of the Ivano-Frankivsk Regional Clinical Hospital in 2009-2016. Fourty-nine (33.7 \%) patients had symptoms of biliary hypertension (BH); in five (3.4\%) of them BH was combined with chronic duodenal obstruction (CDO), the other $5(3.4 \%)$ patients had a combination of BH+C$\mathrm{DP}$ and local venous hypertension of pancreaticobiliary area vessels. Resection-type surgeries were applied in 28 (57.1\%) patients with CP complicated by BH. Intraoperative monitoring of biliary pressure was used in 17 patients in the process of duodenum-preserving resections of the pancreas. Frey's procedure was applied to 20 (71.4 \%) patients, in whom BH persisted after the resection stage of the surgery; Frey's procedure was supplemented by interventions on bile ducts: hepaticoenteroanastomosis was applied in 12 patients, excision of pancreas lingula was applied in one patient, internal biliopancreatic anastomosis was applied in one patient. Berne modification was used in 2 (7.2 \%) patients, and pancreaticoduodenal resection (PDR) according to Whipple - in 6 (21.4\%) patients. Remote results were studied in 19 (67.8 \%) patients. Patients after duodenum-preserving resections had the best quality of life indicators, for BH signs were absent.

Keywords: chronic pancreatitis, biliary hypertension, duodenum-preserving resection, biliary pressure, pancreatic-duodenal resection.
\end{abstract}




\section{Introduction}

Surgical treatment of CP is a topical, complicated and not completely resolved problem of gastroenterology. From 4 to $9 \%$ of patients with CP require surgical intervention [1-7]. Strategies of CP treatment available at present presuppose that the surgery is the last moment of treatment after conservative treatment, change of lifestyle and endoscopic methods failed [8-11].

At present, indications to surgical treatment of CP are not always specific. Surgical treatment is indicated in case of clinical signs of CP and morphological changes in the pancreas when conservative therapy is ineffective and there is a threat of CP complications or the complications have already occurred [1]. The task of surgical treatment of CP include: elimination of pain and local complications, preservation and improvement of exocrine and endocrine functions of the pancreas, improvement of the patients' quality of life [12-16].

Obstruction of the duodenum in cases of CP complicates the course of the disease in 16$36 \%$ of patients, pre-papillary stenosis of the common bile duct (CBD) - in 30-60\%, and compression of mesenteric-portal system - in 11-17\% of patients [17, 18]. Compression of the distal part of the CBD by fibrously-changed lingula plays a significant role in the development of obstructive jaundice in cases of CP [19].

\section{The aim of the research}

Analyze our own results, study and generalize the role of resection surgeries in surgical treatment of CP with $\mathrm{BH}$.

\section{Materials and methods}

Surgical treatment was applied in 145 patients with complicated forms of CP at the department of surgery of the Ivano-Frankivsk Regional Clinical Hospital in 2009-2016. Among them: $134(92.4 \%)$ men and $11(7.6 \%)$ women aged from 21 to 72 . Fourty - nine (33.7\%) patients had symptoms of biliary hypertension $(\mathrm{BH})$, in five $(3.4 \%)$ of them $\mathrm{BH}$ was combined with chronic duodenal obstruction (CDO), the other $5(3.4 \%$ ) patients had a combination of BH+CDP and local venous hypertension of pancreaticobiliary area vessels.

To diagnose $\mathrm{CP}$ and its complications we used: laboratory examinations (levels of alphaamylase, total and direct bilirubin, alkalinephosphatase), ultrasonography (USG), endoscopic retrograde cholangiopancreatography (ERCP), computed tomography (CT), magnetic-resonance cholangiopancreatogpaphy (MRCP), and intraoperative monitoring of biliary pressure (IOMBP).

Patients' quality of life in the remote postoperative periods was considered to be the criterion of surgical treatment efficiency. Assessment of the remote postoperative treatment results was done by examining the patients, USG, and filling out the «Short Form Medical Outcomes Study» (SF-36) questionnaire, which allows evaluating physical and psychoemotional states of the surveyed separately.

\section{Results}

Patients with $\mathrm{CP}$ complicated by $\mathrm{BH}$ underwent resection, draining and palliative surgeries.

Draining surgeries were applied in 14 patients. In particular, 8 (16.3\%) patients underwent longitudinal pancreaticoenterostomy supplemented by biliodigestive anastomoses, 3 (6.1\%) patients - open cystopancreaticoenterostomy on the Roux loop, 2 (4.1\%) patients - endoscopic cystoduodenostomy, one patient - external draining of parapancreatic cyst of the pancreas.

Due to seriousness of the general condition and presence of co-morbidity, palliative surgeries were applied in 7 (16.3\%) patients: application of hepaticoenteroanastomoses - in $2(4.1 \%)$ patients, ERCP with endobiliary stenting -5 (10.2\%) patients.

Resection surgeries were applied in 28 (57.1\%) patients with CP complicated by BH (Table 1). Resection surgeries included: PDR, pylorus-preserving PDR, Beger's procedure, Frey's procedure, longitudinal pancreaticoenterostomy (LPES) with artificial duct formation, Berne modification A manifest chronic inflammatory process in the area of the pancreas was the indication to resection interventions. In case of a grounded assumption of tumorous process in the area of pancreas head, PDR was selected as a method of treatment. 
Table 1

Resection surgeries in patients with chronic pancreatitis accompanied by signs of biliary hypertension

\begin{tabular}{ccc}
\hline Surgery & Number & Percentage, \% \\
\hline Frey's procedure & 20 & 71.4 \\
Standard & 6 & 7.2 \\
With hepaticoenteroanastomosis & 12 & 14.4 \\
With biliopancreaticanastomosis & 1 & 3.6 \\
With excision of pancreas lingula & 1 & 3.6 \\
PDR according to Whipple & 6 & 21.4 \\
Berne modification of Beger's procedure & 2 & 7.2 \\
Total & 28 & 100
\end{tabular}

The patients' stay in the hospital amounted, on average, to 17.5 days. An average period of the patients' stay in the hospital after the surgery was 12.0 days. The duration of the surgery ranged from 210 to 245 minutes, 225 minutes on average.

Remote results of surgical treatment were studied in 19 (67.8\%) patients in the period from 6 to 36 months. The results of filling-out the questionnaire showed that all patients evaluated their physical condition and psychoemotional state as good and satisfactory. Quality of life indicators appeared to be the best after the duodenum-preserving resections. Physical examinations, laboratory and USG data indicated to the absence of $\mathrm{BH}$ signs in these patients in the remote postoperative periods.

\section{Discussion}

Selecting the method of surgical treatment, we took into account the fact that resection surgeries and their modern modifications allow eliminating a number of CP complications, namely: pancreatic duct hypertension, in some cases - biliary hypertension and compression of the porto-splenic-mesenteric confluence with normalization of portal blood circulation (less so for Frey's procedure).

Apart from these positive aspects, resection surgeries decrease functional reserves of the pancreas (exocrine and endocrine functions). In the course of resection surgeries performed strictly observing the technique, $20-40 \%$ of gland parenchyma is deleted, which may lead to stronger functional insufficiency. However, while selecting the method of surgery, we took into account the fact that in patients with complicated forms of CP a part of the parenchyma has already undergone fibrous-degenerative changes and gland tissues have been replaced by connective tissue.

Intra operative monitoring of biliary pressure (patent to useful model No. 101713, bul. No. 18 of 25.09.2015) [20] was performed in 17 patients during duodenum-preserving pancreas resections; in 13 of them biliary pressure (BP) was measured using a digital manometer for pressure measurement connected to a computer. The technique of surgical intervention depended on the results of BP monitoring. If BH persisted after excision of fibrous tissues of the pancreas head and release of the intrapancreatic part of the CBD, the surgery was supplemented by an intervention on bile duct. If BH was eliminated by the surgery on the pancreas, intervention on bile ducts was not applied.

Frey's procedure was applied in $20(71.4 \%)$ patients. Resection stage of the surgery included resection of the head of the pancreas and preservation of the duodenum, as well as longitudinal pancreaticoenterostomy along the body and tail of the pancreas. Isolated damage of the pancreas head by fibrous process and Wirsung's duct ectasia without adjacent organ dysfunction were considered the indications to Frey's procedure. Elimination of a large part of the pancreas parenchyma together with degeneratively changed nervous fibers and parenchymal calcifications was mandatory. Counter-indications to Frey's procedure included constriction of the upper mesenteric vein with development of regional portal hypertension, duodenal dystrophy, and impossibility to exclude tumorous nature of the disease.

Completion of the standard Frey's procedure had several variants. At the first stage of the research, we used two-layer suture when applying pancreaticoenteroanastomoses (8 patients). At the 
second stage, one-layer continuous suture using Vicryl (3-0 or 4-0) or PDS (4-0) on the non-traumatic intestinal needle was used.

Standard Frey's procedure with application of pancreaticoenteroanastomosis on a long loop according to Roux was applied in 2 (7.1\%) patients (Fig. 1, 2). At the reconstruction stage, using the edges of the cavity in the head of the pancreas and open Wirsung's duct, we shaped a minimum $60 \mathrm{~cm}$ long anastomosis with a Roux-loop put through the mesenteriolum of the transverse colon.

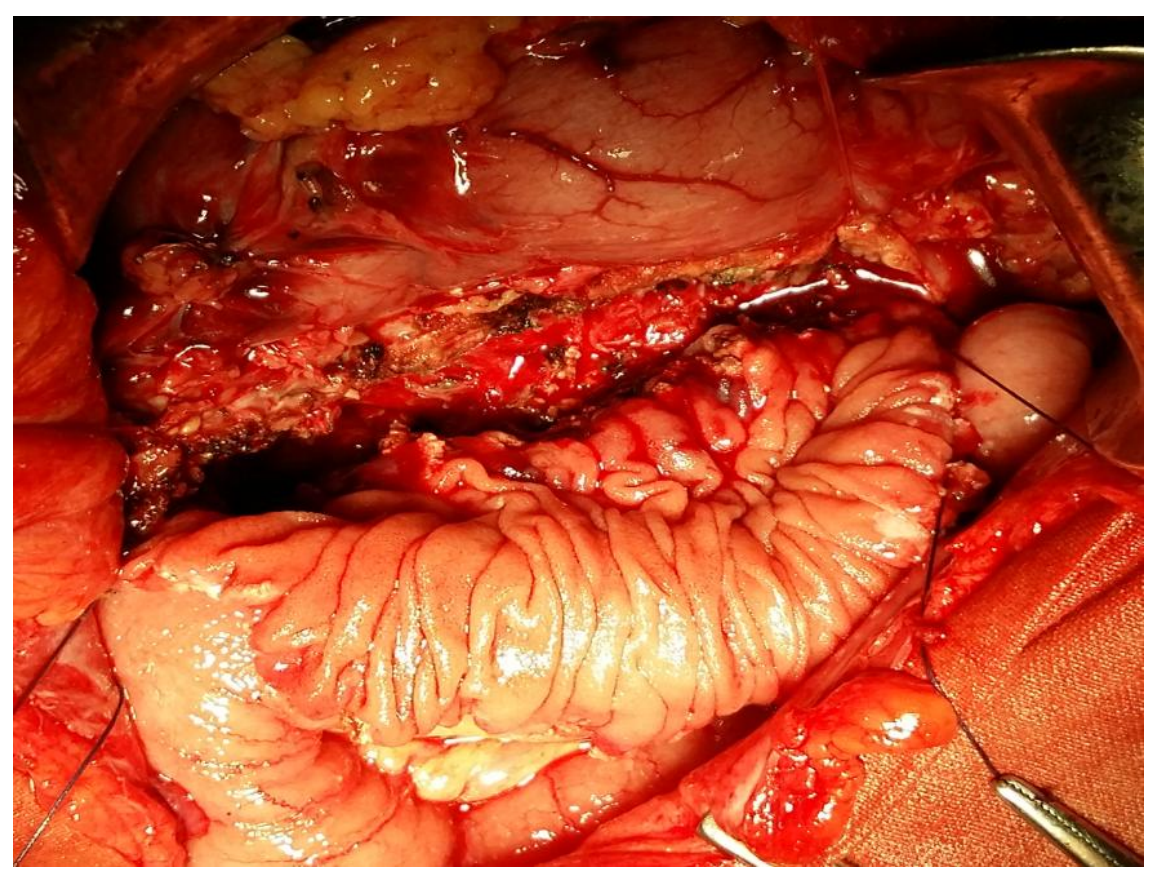

Fig. 1. Frey's procedure. Application of pancreaticoenteroanastomosis

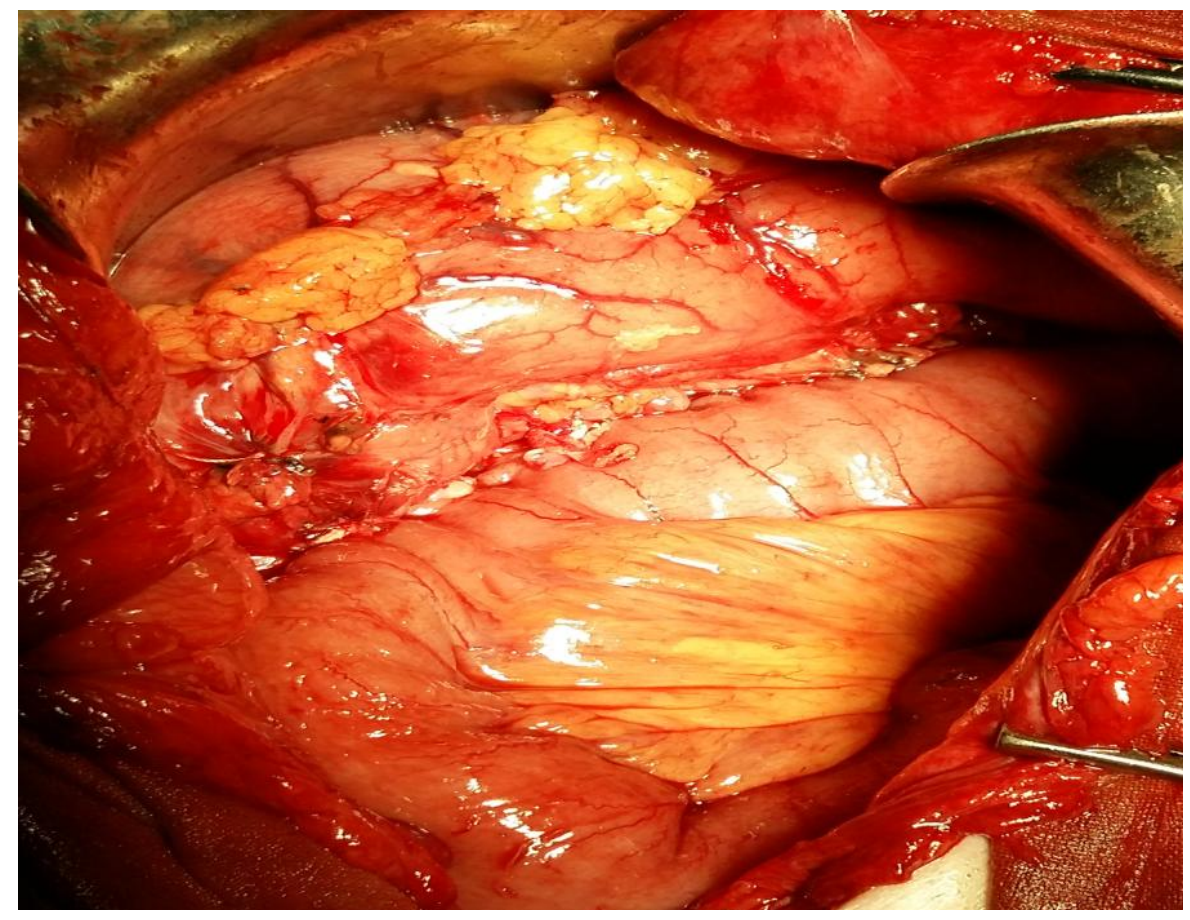

Fig. 2. Frey's procedure. Completion of shaping pancreaticoenteroanastomosis 
Standard Frey's procedure with application of pancreatico-jejuno-duodeno-anastomosis on an isolated loop according to V. M. Kopchak was applied in 4 (14.2\%) patients (Fig. 3). At the reconstruction stage of the surgery, this method meant cutting out a transplant from the small intestine on a vascular pedicle with a length corresponding to the length of the dissected pancreatic duct and duodenum with further application of pancreaticojejunoanastomosis and duodenojejunoanastomosis between the small intestine transplant and the descending part of the duodenum in the projection of the duodenal ampulla.

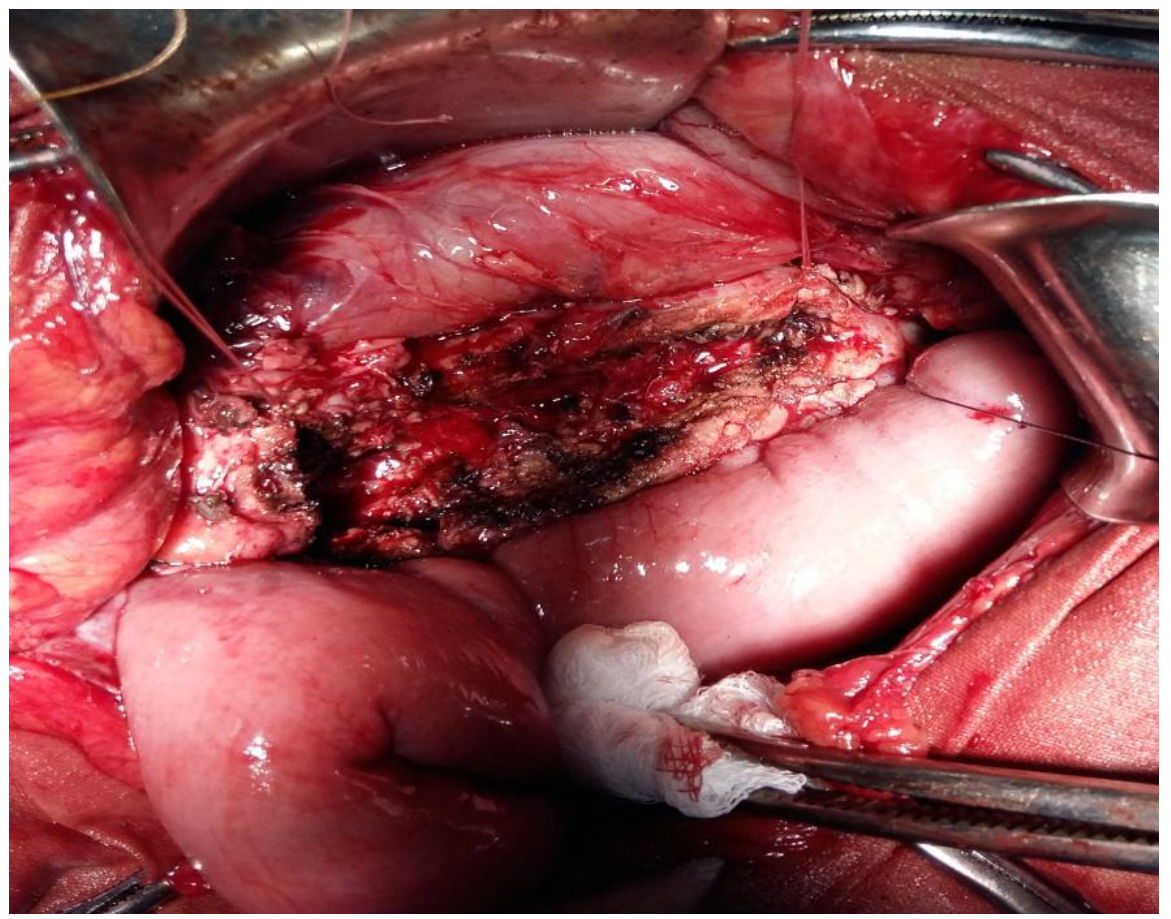

Fig. 3. Frey'sprocedure. Shaping the pancreatico-jejuno-doudenoanastomosis on isolated loop according to V. M. Kopchak

In $14(70 \%)$ patients, in whom BH persisted after the resection stage of the surgery, Frey's procedure was supplemented by intervention on bile ducts: hepaticoenteroanastomosis was applied in 12 patients, excision of the lingula of the pancreas - in one patient, and biliopancreatic anastomosis - in one patient.

Postoperative complications after the Frey's procedure appeared in $2(10 \%)$ patients. One of them had an early adhesive small bowel obstruction on the $5^{\text {th }}$ day, which was eliminated during the repeated surgical intervention. Another patient had developed acute intestinal bleeding from the acute erosions and ulcers of the stomach and duodenum IIB according to the Forrest endoscopic hemorrhage classification, which was eliminated by conservative means. One patient of this group died (postoperative mortality $-5 \%$ ) due to a hemorrhage and insufficiency of pancreaticojejunoanastomosis sutures. Other patients had no complications in the postoperative period, they were discharged from the hospital in a satisfactory condition. Patients' stay in the hospital ranged from 9 to 21 days, 12.8 days on average. Average period of the patients' stay in the hospital after the surgery amounted to 10.5 days.

Beger's procedure (Berne modification) was applied in $2(7.2 \%)$ patients with CP. It was performed in cases of CP with the majority of damage of the head of the pancreas and little changes in the ducts of the body and tail of the gland. In the course of this intervention, we managed to eliminate $\mathrm{BH}$ in patients of both groups by releasing the intrapancreatic part of the CBD from fibrous-degenerative tissues, therefore, biliodigestive anastomoses were not used. Postoperative complications were not witnessed. 
Pancreaticoduodenal resection according to Whipple was applied in 6 (21.4\%) patients (Fig. 4). Indications to PDR on the "capitate" pancreatitis included:

- impossibility to exclude malignant process in the head of the pancreas ( 2 patients). We believe that preoperative thin needle biopsy of the pancreas head is not always informative in terms of differential diagnostics of $\mathrm{CP}$ and pancreas cancer;

- significantly enlarged head of the pancreas, which simultaneously caused compression of the duodenum, CBD, and vessels of the pancreaticoduodenal area (3 patients). PDR allows simultaneous elimination of all three complications of $\mathrm{CP}$;

- intrapancreatic cysts on the head of the pancreas with defined defect in the anterosuperior pancreaticoduodenal artery, which caused multiple hermorrhages into the lumen of the cyst and gastro intestinal tract (1 patient). Selective angiography and artery occlusion were technically impossible in this case.

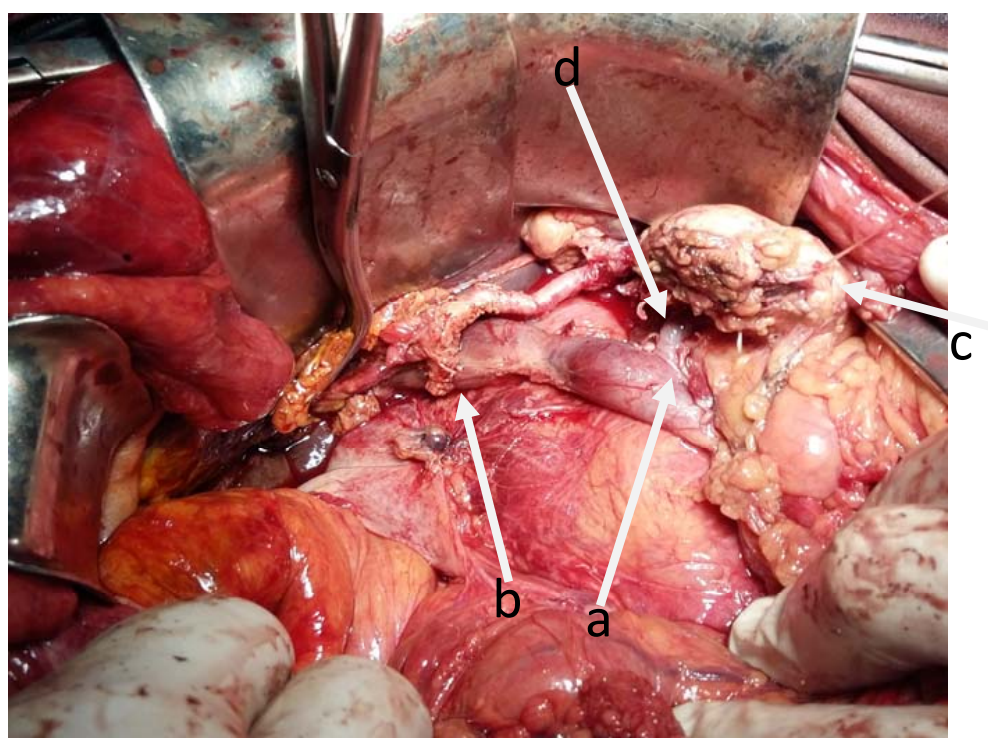

Fig. 4. PDR. Resection stage: $a-\mathrm{v}$. Portae released from fibrous tissues; $b$ - common bile duct stump; $c$ - pancreatic stump; $d-$ a. hepatica

At the reconstruction stage of the surgery, we applied embolic termino- terminal pancreatico-enteroanastomosis ( 3 patients) or termino-lateral pancreatico-enteroanastomosis ( 3 patients) (on a selected loop of the small intestine $10-15 \mathrm{~cm}$ below the Treitz's ligament) with subsequents shaping of the termino-lateral hepatico-enteroanastomosis on one loop behind the segmented intestine (according to O. O. Shalimov, V. M. Kopchak) at a distance of $15-20 \mathrm{~cm}$ from pancreaticoenteroanastomosis.

On the fourth day after the surgery, bile leakage from drainages was found in one patient. In the course of the relaparotomy, a defect of hepaticocholedochus was found above the hepaticoenteroanastomosis line (qualified as thermal intraoperative trauma resulting from diathermocoagulation); the defect was sutured. Gastrostasis was found in 3 patients in the early postoperative period, which influenced the duration of treatment of these patients in general. To eliminate gastrostasis, we applied conservative treatment, which included mandatory decompression of the stomach, administration of prokinetics and gastric secretion inhibitors. Signs of gastrostasis were eliminated in all patients on the $9^{\text {th }}-10^{\text {th }}$ day.

\section{Conclusions}

1. The surgeries elected to treat patients with $\mathrm{CP}$ accompanied by signs of $\mathrm{BH}$ are duodenum-preserving resections (Frey's procedure, Beger's procedure, Berne modification), which in some cases require additional interventions on bile passages (application of biliodigestive or biliopancreatic anastomoses in the area of pancreas head resection).

2. Intraoperative monitoring of biliary pressure allows detection of non-manifest $\mathrm{BH}$ and selection of an adequate scope of surgery in patients with $\mathrm{CP}$ accompanied by BH. 


\section{References}

[1] Kopchak, V. M., Kopchak, K. V., Pererva, L. A., Duvalko, A. V. (2012). Surgical treatment of chronic pancreatitis. Health of Ukraine, 1 (7), 18-19.

[2] Galperin, E. I. (2009). Chronic pancreatitis. Annals of surgical hepatology, 14 (3), 92-111.

[3] Lankisch, P. G. (2007). Chronic pancreatitis. Current Opinion in Gastroenterology, 23 (5), 502-507. doi: 10.1097/mog.0b013e3282ba5736

[4] Grishin, I. N., Gric, V. N., Lagodich, S. N. (2009). Cysts, fistula of pancreas and its complications. Minsk: High school, 270.

[5] Buchler, M. W., Friess, H., Uhl, W., Malfertheiner, P. (2002). Cronic pancreatitis. Novel concepts and therapy. Blackwell Wissenschafts - Verlag A Blackwell publishing company, 614.

[6] Aljarabah, M., Ammori, B. J. (2007). Laparoscopic and endoscopic approaches for drainage of pancreatic pseudocysts: a systematic review of published series. Surgical Endoscopy, 21 (11), 1936-1944. doi: 10.1007/ s00464-007-9515-2

[7] Beger, H. G., Matsuno, S., Cameron, J. L. (Eds.) (2008). Diseases of the Pancreas. Springer Verlag Berlin Heidelberg, 259-291. doi: 10.1007/978-3-540-28656-1

[8] Yang, C., Bliss, L., Freedman, S., Sheth, S., Ng, S. C., Kent, T. et. al (2014). A single-center analysis of surgical treatment for chronic pancreatitis: relatively rare and unevenly deployed. Pancreatology, 14 (3), S40. doi: 10.1016/j.pan.2014.05.513

[9] Rutter, K., Ferlitsch, A., Sautner, T., Püspök, A., Götzinger, P., Gangl, A., Schindl, M. (2010). Hospitalization, Frequency of Interventions, and Quality of Life after Endoscopic, Surgical, or Conservative Treatment in Patients with Chronic Pancreatitis. World Journal of Surgery, 34 (11), 2642-2647. doi: 10.1007/s00268-010-0713-z

[10] Strate, T., Bachmann, K., Busch, P., Mann, O., Schneider, C., Bruhn, J. P. et. al (2008). Resection vs Drainage in Treatment of Chronic Pancreatitis: Long-term Results of a Randomized Trial. Gastroenterology, 134 (5), 1406-1411. doi: 10.1053/j.gastro.2008.02.056

[11] Cahen, D. L., Gouma, D. J., Nio, Y., Rauws, E. A. J., Boermeester, M. A., Busch, O. R. et. al (2007). Endoscopic versus Surgical Drainage of the Pancreatic Duct in Chronic Pancreatitis. New England Journal of Medicine, 356 (7), 676-684. doi: 10.1056/nejmoa060610

[12] Büchler, M. W., Baer, H. U., Seiler, C. (1997). Duodenum preserving resection of the head of the pancreas: a standard procedure in chronic pancreatitis. Chirurgie, 68 (4), 364-368.

[13] Müller, M. W., Friess, H., Martin, D. J., Hinz, U., Dahmen, R., Büchler, M. W. (2008). Longterm follow-up of a randomized clinical trial comparing Beger with pylorus-preserving Whipple procedure for chronic pancreatitis. British Journal of Surgery, 95 (3), 350-356. doi: 10.1002/bjs.5960

[14] Farkas, G., Leindler, L., Daróczi, M., Farkas, G. (2010). Ten-Year Experience With Duodenum and Organ-Preserving Pancreatic Head Resection (Büchler-Farkas Modification) in the Surgical Treatment of Chronic Pancreatitis. Pancreas, 39 (7), 1082-1087. doi: 10.1097/mpa.0b013e3181d3727b

[15] Diener, M. K., Rahbari, N. N., Fischer, L., Antes, G., Büchler, M. W., Seiler, C. M. (2008). Duodenum-preserving Pancreatic Head Resection Versus Pancreatoduodenectomy for Surgical Treatment of Chronic Pancreatitis. Annals of Surgery, 247 (6), 950-961. doi: 10.1097/sla.0b013e3181724ee7

[16] Köninger, J., Seiler, C. M., Sauerland, S., Wente, M. N., Reidel, M. A., Müller, M. W. et. al (2008). Duodenum-preserving pancreatic head resection - A randomized controlled trial comparing the original Beger procedure with the Berne modification (ISRCTN No. 50638764). Surgery, 143 (4), 490-498. doi: 10.1016/ j.surg.2007.12.002

[17] di Sebastiano, P., di Mola, F. F. (2013). Pathophysiology of Chronic Damage. Acute and Chronic Pancreatitis: New concepts and evidence-based approaches. Turin: Edizioni Minerva Medica, 63-69.

[18] Ceyhan, G. O., Michalski, C. W., Demir, I. E., Müller, M. W., Friess, H. (2008). Pancreatic pain. Best Practice \& Research Clinical Gastroenterology, 22 (1), 31-44. doi: 10.1016/j.bpg.2007.10.016

[19] Kopchak, V. M., Usenko, A. Yu., Kopchak, K. V., Zelinskiy, A. I. (2011). Surgical anatomy of pancreas. Kyiv: «Askania», 141.

[20] Pylypchuk, V. I., Kopchak, V. M., Shevchuk, I. M. (2015). Patent 101713 Ukraine, IPC (International Pattent Classification) A 61B 17/00. Method of surgical treatment of chronic pancreatitis complicated by gallstone disease. № u 2015 03315. appl. 09.04.2015; publ. 25.09.2015; Bul. № 18. 